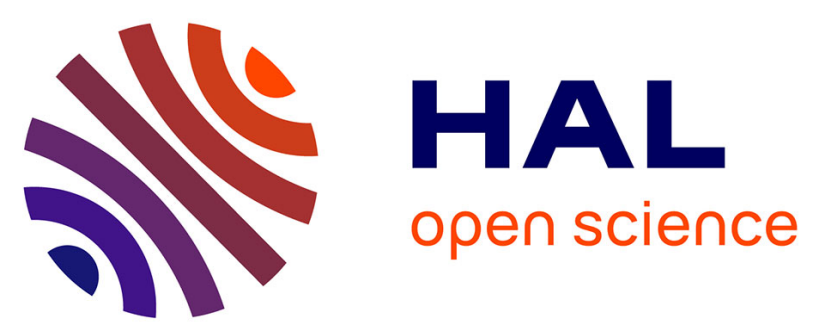

\title{
Research on Prediction Model and Characteristic Parameters on Dry Matter Accumulation in Wheat Based on Normalized Method and Grey System
} Juan Liu, Xiaoli Zhao, Shuping Xiong, Xinming Ma, Yanfeng Wang, Jing Wang

\section{To cite this version:}

Juan Liu, Xiaoli Zhao, Shuping Xiong, Xinming Ma, Yanfeng Wang, et al.. Research on Prediction Model and Characteristic Parameters on Dry Matter Accumulation in Wheat Based on Normalized Method and Grey System. 6th Computer and Computing Technologies in Agriculture (CCTA), Oct 2012, Zhangjiajie, China. pp.142-149, 10.1007/978-3-642-36137-1_18 . hal-01348226

\author{
HAL Id: hal-01348226 \\ https://hal.inria.fr/hal-01348226
}

Submitted on 22 Jul 2016

HAL is a multi-disciplinary open access archive for the deposit and dissemination of scientific research documents, whether they are published or not. The documents may come from teaching and research institutions in France or abroad, or from public or private research centers.
L'archive ouverte pluridisciplinaire HAL, est destinée au dépôt et à la diffusion de documents scientifiques de niveau recherche, publiés ou non, émanant des établissements d'enseignement et de recherche français ou étrangers, des laboratoires publics ou privés. 


\title{
Research on Prediction Model and Characteristic Parameters on Dry Matter Accumulation in Wheat Based on Normalized Method and Grey System
}

\author{
Juan Liu ${ }^{1}$, Xiaoli Zhao ${ }^{2}$, Shuping Xiong ${ }^{1}$, Xinming Ma ${ }^{1,2 *}$, \\ Yanfeng Wang ${ }^{1}$, and Jing Wang ${ }^{1}$ \\ ${ }^{1}$ Key Laboratory of Physiology, Ecology and Genetic Improvement of \\ Food Crops in Henan Province, College of Agronomy, Henan Agriculture \\ University, Zhengzhou Henan, China \\ ${ }^{2}$ College of Information and Management Science, Henan Agriculture \\ University, Zhengzhou Henan, China \\ Xinmingma@126.com, Liujuanviolet@163.com
}

\begin{abstract}
To investigate a model to simulate wheat dry matter accumulation, three wheat cultivars with different tillering abilities were grown at three densities each in a field experiment. Five simulation models with high correlation coefficients for relative dry matter accumulation were established by the method of normalized. Among these models, the Richards equation was the best in fitting and forecasting, i.e., $y=1.1435 /\left(1+\mathrm{e}^{0.2776-4.6558 x}\right)^{1 / 0.1130}, r=0.9927$. Correlation coefficient of grey comprehensive relationship degree between actual dry matter accumulation in occurrence time of maximum rate of dry matter accumulation and dry matter weight was highest, so a higher actual dry matter weight in occurrence time of maximum rate of dry matter accumulation played an important role in stabilizing and improving dry matter weight of wheat.
\end{abstract}

Keywords: Wheat, Dry matter accumulation, Simulation model, Characteristic parameters.

${ }^{*}$ Correesponding author: Xinmingma; Telephone: 13592643698; Email: xinmingma@126.com 


\section{Introduction}

Wheat is one of the most important grain crops in China; over 95\% of its yield is based on photosynthesis. Dry matter accumulation is the final product of wheat photosynthesis, and closely related to the yield formation [1-2]. Regulation and control of many cultivation factors affect the wheat dry matter accumulation, among them density is the important factor which affect the wheat growth and development and yield [3]. So it has great significance to clear the high yield or even super high yield in wheat by investigating the relationship between density and dry matter accumulation. Dry matter accumulation appears S-shape during the whole life of wheat, and has obvious differences in different densities [4]. There are great differences among those tillering abilities of wheat in different cultivars, so it is necessary to study the evolution law of dry matter accumulation process with different densities and tillering abilities of wheat cultivars.

Crop simulation technology can quantitatively describe the process of crop growth [5]. At present, there has been created some simulation models on photosynthetic production and dry matter accumulation of wheat [6-7], but those models have stronger mechanism, and more parameters which were more difficulty to get, so their practicability was obvious limited. Empirical models mostly used Richards or Logistic equation to simulate the process of dry matter accumulation in wheat [8-9], However, some other researchers hold that the time scale, which measured on the process of crop growth and development, should be selected reasonably[10]. For example, ecological variables such as accumulated temperature, are more representative than time variables that of days, and they can also reflect the status of crop growth better. In order to investigate the relationship between density, tillering ability and dry matter accumulation of wheat, provide the theoretical basis for prediction on wheat growth and culture of high yield, making research based on field experiment, and taking the accumulated temperature as time scale, a prediction model, which is suitable for dynamic dry matter accumulation with different densities and tillering abilities of wheat, was tried to create with the method of normalization[11]. 


\section{Materials and Methods}

\subsection{Experimental Design}

Field experiments were conducted during 2009 2011 at the Experimental Station of the Henan Agricultural University, Zhengzhou, PR China. The cultivars studied were medium tillering ability and high earing rate wheat (YM49-198), stronger tillering ability and low earing rate wheat (LKAZ8) and stronger tillering ability and high earing rate wheat (YZ4110). Seeds were sown on 14th October 2009 and 15th October 2010, which produced with densities of 750,000, 2, 250, 000, and 3,750,000 plants $\mathrm{hm}^{-2}$ in randomized block design. The field was also managed as same as high yield wheat field.

\subsection{Measure Items and Methods}

Choosing 200 strains wheat seedling in uniform growth state at three leaf period of wheat, marking those wheat seedling with label, and sampling every 10 days from three leaf period to wintering stage, every 30 days from wintering stage to returning green stage, and every 10 days from returning green stage to maturity, dry matter of 10 20 samples were measured each time. Weighing and calculating the dry matter accumulation of aerial part in unit land area (DMA for short).

\subsection{Meteorological Data}

The meteorological data was come from Meteorological Bureau of Henan, mainly including maximum temperature, minimum temperature daily during the growth period of wheat and so on. Calculation method of daily mean temperature is using an equation $T_{i}=\left(T_{\text {imax }}+T_{(i+1) \min }\right) / 2$, where $T_{i}$ is mean temperature of the $i$ day, $T_{i \max }$ is the maximum temperature of the $i$ day and $T_{(i+1) \min }$ is the minimum temperature of the $i+1$ day. Calculation method of accumulated temperature is $A T_{i}=\sum T_{i}$, where $A T_{i}$ is the accumulated temperature of the $i$ day, while if $T_{i} \leqslant 0^{\circ} \mathrm{C}$ or $T_{i} \geqslant 35^{\circ} \mathrm{C}$, then $T_{i}=0^{\circ} \mathrm{C}$ [12]. 


\subsection{Normalized Treatment of Data}

Define the maximum dry matter accumulation $\left(D M A_{\max }\right)$ the maximum accumulated temperature $\left(A T_{\max }\right)$ to 1 (using the data of 2009 2010), the relative dry matter accumulation $\left(R D M A_{i}\right)$ and relative accumulated temperature $\left(R A T_{i}\right)$ were obtained with the method of normalization [11], using the equations as follows: $R D M A_{i}=D M A_{i} / D M A_{\max }, R A T_{i}=A T_{i} / A T_{\max }$. The $D M A_{i}$ is the dry matter accumulation in different growth stages, $R D M A_{i}$ is the relative dry matter accumulation in different growth stages, $R A T_{i}$ is the relative accumulated temperature in different growth stages. The value of $R D M A_{i}$ and $R A T_{i}$ were $0 \sim 1$. The experiment data have been fitted by soft of Curve Expert 1.38, statistical analyzed by SPASS 13.0, and mapped by Sigmaplot in this paper.

\subsection{Model}

Using the experiment data of 2010 2011 as data, the accuracy of simulation model of RDMA was tested [13].

\section{Results and Analysis}

\subsection{Established and Screened of RDMA Models}

Treating $A T$ and $D M A$ that from seeding stage to maturity period of wheat by the method of normalization, and fitting the relationship between RAT and RDMA by soft of Curve Expert 1.38, five mathematical equations in Table 1 which have higher correlation coefficient were got. The limit value of the 5 fitting equations show that simulation equations of (1), (2), (3) could not explain the DMA process, but (4) and (5) could reflect the law of DMA dynamic changes. Equation (5) is a special case of (4), and it could be transformed from (4) when $d=1$. So equation (4), the Richards equation was chosen to simulate the relationship of $R D M A$ and $R A T$ in this paper. The Richards curve equation was fitted as follows:

$y=1.1435 /\left(1+e^{0.2776-4.6558 \cdot x}\right)^{1 / 0.1130}$. 
Table 1. Relative dry matter accumulation models of wheat

\begin{tabular}{ccccccccc}
\hline \multirow{2}{*}{ Simulated equations } & \multicolumn{4}{c}{ Coefficients } & & $\begin{array}{c}\text { Standard } \\
\text { deviation }\end{array}$ & $\begin{array}{c}\text { Correlation } \\
\text { coefficient }\end{array}$ & y value \\
\cline { 2 - 9 } & $a$ & $b$ & $c$ & $d$ & SD & $r$ & $x \rightarrow \infty$ \\
\hline$y=a+b x+c x^{2}+d x^{3} .(1)$ & 0.130 & -1.573 & 5.863 & -3.412 & 0.044 & $0.993^{* * *}$ & $\infty$ \\
$y=a+b \cos (c x+d) .(2)$ & 0.512 & 0.497 & 3.645 & 2.622 & 0.044 & $0.993^{* *}$ & $\infty$ & 1.3 \\
$y=\left(a b+c x^{d}\right) /\left(b+x^{d}\right) .(3)$ & 0.009 & 0.179 & 1.206 & 3.573 & 0.045 & $0.993^{* *}$ & $0.993^{* *}$ & 1 \\
$y=a /\left(1+\mathrm{e}^{b-c x}\right)^{(1 / d)} .(4)$ & 1.144 & 0.278 & 4.656 & 0.113 & 0.045 & $0.992^{* *}$ & 1 \\
$y=a /\left(1+b \mathrm{e}^{-c x}\right) .(5)$ & 1.047 & 89.652 & 7.698 & & 0.048 & & \\
\hline
\end{tabular}

${ }^{1}$ In these equations $x$ and $y$ denoted $R A T$ and $R D M A$, respectively. ** denoted $\mathrm{P}<0.01$. $a$ denoted relative maximum increment; $b$ denoted initial value of parameter; $c$ denoted growth rate parameters; $d$ denoted shape parameter; The same below.

\subsection{Validation of RDMA Models in Wheat}

The RDMA models of wheat were tested using the data of 2010 2011 as validation data, Fig. 1 shows that the simulated values exhibited significant positive correlation with the measured values, correlation coefficients were all more than 0.97 . The accuracies of simulation were all over 0.91 , and increased with the increase of density. Through the deduced of Richards equation, characteristic parameters with biological significance would be obtained, and they could be used to analyze the dynamic characteristics of DMA in wheat quantitatively.

Fig. 1. Relationship between the simulated and measured dry matter accumulation of wheat

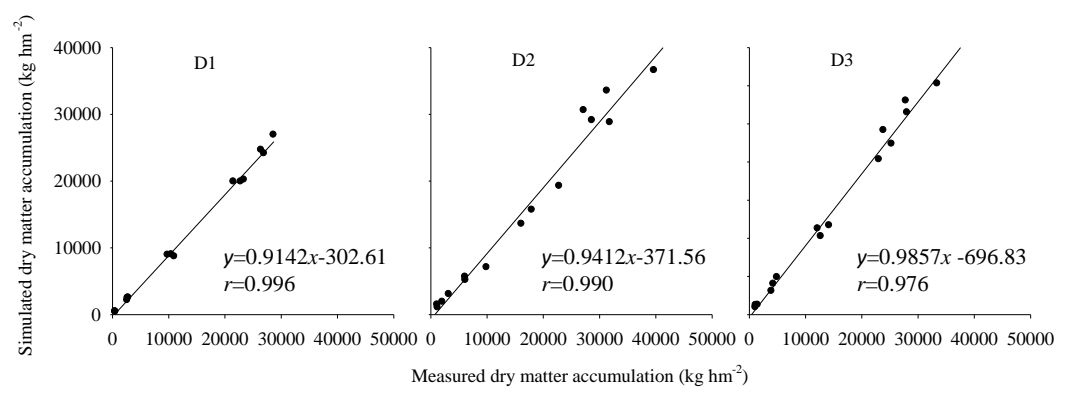




\subsection{Characteristic Parameters Analysis of Wheat}

After derivation calculus to the equation $y=a /\left(1+e^{(b-c x)}\right)^{1 / d}$, variation rate of $R D M A$ equation was got as follows:

$$
\frac{d y}{d x}=\frac{a \cdot c \cdot e^{(b-c \cdot x)}}{d \cdot\left(1+e^{(b-c \cdot x)^{(d+1) / d}}\right)}
$$

Mean relative growth rate of $D M A$ and the maximum relative accumulation rate of dry matter during the whole growth were obtained by integral to equation (7). Meanwhile, the characteristic parameters, such as RAT and RDMA, at the fastest stage were also derived [14-15].

$$
\begin{aligned}
& G=\frac{1}{a} \int_{0}^{a} \frac{d y}{d x} d x=\frac{a \times c}{2(d+2)} . \\
& A R A T=(b-\ln d) / c . \\
& A R_{\max }=\frac{a \times c}{(1+d)^{(d+1) / d}} . \\
& A R D M A=\frac{a}{(1+d)^{1 / d}} .
\end{aligned}
$$

Where $G$ is the mean relative growth rate of DMA, ARAT is $R A T$ in occurrence time of maximum rate of $D M A, A R_{\max }$ is the maximum relative accumulating rate of dry matter accumulation, ARDMA is $R D M A$ in occurrence time of maximum rate of dry matter accumulation. The values of these characteristic parameters were obtained by using the value of $a, b, c, d$ in equation (4), $G=1.26$, $A R A T=0.53, A R_{\max }=1.86, A R D M A=0.44$. So $R A T$ is 0.53 when $A R_{\max }$ appears, and at this time $D M A$ was almost half of total $D M A$. The actual accumulated temperature in occurrence time of maximum rate of dry matter accumulation (ARAT ' ), actual dry matter accumulation in occurrence time of maximum rate of dry matter accumulation $\left(A R D M A^{\prime}\right)$, mean actual growth rate of dry matter accumulation $\left(G^{\prime}\right)$, and maximum actual accumulating rate of dry matter accumulation $\left(A R_{\max }{ }^{\prime}\right)$ could be derived by using the value of $D M A_{\max }$ and $A T_{\max }$ when $A R_{\max }$ appears.

In order to determine the relative importance of characteristic parameters to dry matter weight, using the grey system comprehensive relationship degree to analyze the relationship between dry matter weight and characteristic parameters. Consider 
the dry matter weight as system characteristic behavior sequence:

$X_{i}=\left(x_{i}(1), x_{i}(2), \ldots, x_{i}(n)\right)$.

Consider characteristic parameters as related factors sequence:

$X_{j}=\left(x_{j}(1), x_{j}(2), \ldots, x_{j}(n)\right)$.

Calculated grey comprehensive relationship degree between each of them. Grey comprehensive relationship degree not only embodied the similar degree between the two sequences, but also reflected the approaching of the change rate with characteristic behavior sequence and related factors sequence relative to the starting point respectively. Meanwhile, it was a quantitative index to characterize more comprehensive if the relationship of sequences are close, and the calculation formula is

$$
\rho_{0 i}=\theta \varepsilon_{0 i}+(1-\theta) \gamma_{0 i}, \theta \in[0,1] \text {. }
$$

Where $\varepsilon_{0 i}$ is absolute correlation degree, $\gamma_{0 i}$ is relative correlation degree, and $\theta=0.5$. From Table 2 , the results of correlation degree analysis show that the correlation coefficients between dry matter weight and characteristic parameters of wheat $A R A T^{\prime}, A R_{\max }{ }^{\prime}$, $A R D M A^{\prime}, G^{\prime}$ were all above 0.6. The correlation coefficients of $A R D M A^{\prime}$ and dry matter weight was 0.861 , and then decreased in order of: $A R_{\max }{ }^{\prime}, G^{\prime}$ and $A R A T^{\prime}$. Therefore, the effect of $A R D M A^{\prime}$ ' on dry matter production was most important, higher $A R D M A^{\prime}$ plays a very important role to improve dry matter weight of wheat.

Table 2. Analysis on dry matter weight and characteristic parameters of wheat based on grey comprehensive correlative degree

\begin{tabular}{ccccc}
\hline \multirow{2}{*}{ Item } & \multicolumn{4}{c}{ Correlation coefficients } \\
\cline { 2 - 5 } & $A R A T^{\prime}$ & $A R_{\max }{ }^{\prime}$ & $A R D M A^{\prime}$ & $G^{\prime}$ \\
\hline Dry matter weight & 0.647 & 0.724 & 0.861 & 0.718 \\
\hline
\end{tabular}

\section{Conclusion and Discussion}




\subsection{Established Model and Its Characteristics of Wheat DMA}

Wu et al [16] established DMA mechanism models, which had stronger interpretability and the parameters had physical meaning. However there were too many parameters in the model. Empirical models with less parameters, but they were only used to describe. Crop growth model should be established by combined the method of mechanism and empirical [17]. Analyzing the characteristics of dynamic DMA in wheat, mainly using time variable as the scale of growth and development in the past [18]. Therefore, using the normalized method and making accumulated temperature as time scale. Richards equation was established in this paper as $y=1.1435 /\left(1+e^{0.2776-4.6558 \cdot x}\right)^{1 / 0.1130}(\mathrm{r}=0.9927)$, it improved generality of the model, overcome the defects of model parameters changes that cultivation measures and varieties caused. The Richards equation has less parameters and good biological significance. The production process of wheat could be predicted by DMA which be simulated through the model and accumulated temperature in any growth period.

\subsection{Research on Characteristic Parameters of Dry Matter Accumulation in Wheat}

By deduced of simulation equation, characteristic parameters with biological significance would be obtained. Dynamic characteristics of crop dry matter accumulation have been analyzed by many scholars [19-20]. As the results show, $R A T$ at the maximum rate of dry matter accumulation was 0.53 , meanwhile, DMA was almost half of total $D M A$. This proved that strengthening field management in early stage of wheat growth, cultivating sound seedlings and constructing proper population structure were important to high yield of wheat. Correlation coefficient of grey comprehensive relationship degree between $A R_{\max }{ }^{\prime}, A R A T^{\prime}, G^{\prime}$ and final dry matter weight were more than 0.6. The highest correlation coefficient was between $A R D M A^{\prime}$ ' and dry matter weight which was 0.861 proved that $A R D M A$ ' effects the dry matter weight most. A higher ARDMA' played an important role in stabilizing and improving dry matter weight of wheat. 
Acknowledgments. This research was supported by grants from the Special Research Foundation of Agriculture Industry (201103001), National Natural Science Fund (30771266) and the System of Industrial Technologies for Modern Agriculture of Henan Province (S2010-01-G04).

\section{References}

1. Yao, S.-M., Kang, Y.-H., Liu, H.-J.: Studies on dry matter accumulation, partitioning and translocation in winter wheat under sprinkler and surface irrigation conditions. Agricultural Research in the Arid Areas. 26(6), 51-56 (2008) (in Chinese)

2. Dordas, C.A., Sioulas, C.: Dry matter and nitrogen accumulation, partitioning, and retranslocation in safflower (Carthamus tinctorius L.) as affected by nitrogen fertilization. Field. Crop. Res. 110(1), 35-43 (2009)

3. Hiltbrunner, J., Streit, B., Liedgens, M.: Are seeding densities an opportunity to increase grain yield of winter wheat in a living mulch of white clover? Field. Crop. Res. 102(3), 163-171 (2007)

4. Su, Z.-G., Yang, W.-B., Tian, J.-C., Song, G.-Z.:The relationships between soluble sugar contents of plant and kernel and dry matter accumulation in different high yielding wheat genotypes. Chinese Agricultural Science Bulletin. 23(9), 307-311(2007) (in Chinese)

5. Cao, H.-X., Zhao, S.-L., Ge, D.-K., Liu, Y.-X., Liu, Y., Sun, J.-Y., Yue, Y.-B., Zhang, Z.-Y., Chen, Y.-L.: Discussion on development of crop models. Scientia Agricultura Sinica. 44(17), 3520-3528 (2011) (in Chinese)

6. Liu, T.-M., Cao, W.-X., Luo, W.-H., Wang, S.-H., Yin, J.: A simulation model of photosynthetic production and dry matter accumulation in wheat. Journal of Triticeae Crops. 21(3), 26-31 (2001) (in Chinese)

7. Zheng, Y.-F., Yan, J.-Y., Wan, C.-J., Ge, H.-M., Yang, Z.-M.: Numerical study of wheat photosynthetic production. Journal of Nanjing Institute of Meteorology. 18(4), 566-571 (1995) (in Chinese)

8. Goudriaan, J., Van Laar, H.H.: Modelling Potential Crop Growth Processes. Textbook with Exercises. Kluwer Academic Publishers, Dordrecht (1994)

9. Cao, W., Moss, D.N.: Modelling phasic development in wheat: a conceptual integration of physiological components. J. Agr. Sci. 129(2), 163-172 (1997)

10. Lü, X.: Studies on Effects of Ecological Factors on Growth of Maize and Establishment of Climate Ecology Model and Appraisement 
System. Shandong Agricultural University, Taian (2006) (in Chinese)

11. Zhang, B., Zhao, M., Dong, Z.-Q., Li, J.-G., Chen, C.-Y., Sun, R.: Establishment and test of LAI dynamic simulation model for high yield population. Acta Agronomica Sinica. 33(4), 612-619 (2007) (in Chinese)

12. Xiao, J., Li, N., Jiang, H.-F.: Calculation and stability of accumulated temperatures in the growing season of winter wheat. Journal of Meteorological Research and Application. 3(12), 64-67 (2010) (in Chinese)

13. Fu, X.-L., Zhao, M., Zhou, B.-Y., Cui, G.-M., Ding, Z.-S.: Optimal model for dynamiccharacteristics of grain weight commonly used in wheat and maize. Acta Agronomica Sinica. 35(2), 309-316 (2009) (in Chinese)

14. Li, X.-L., Zhao, M., Li, C.-F., Ge, J.-Z., Hou, H.-P., Li, Q., Hou, L.-B.: Effect of sowing-date and planting density on dry matter accumulation dynamic and establishment of its simulated model in maize. Acta Agronomica Sinica. 36(12), 2143-2153 (2010) (in Chinese)

15. Li, Y.-D., Tang, L., Chen, Q.-C., Zhang, Y.-P., Cao, W.-X., Zhu, Y.: Dry matter accumulation in rice aboveground part: quantitative simulation. Chinese Journal of Applied Ecology. 21(6), 1504-1510 (2010) (in Chinese)

16. Wu, R.-J., Zheng, Y.-F.: A dynamical model of photosynthetic production and dry matter accumulation in wheat under increment UV$\mathrm{B}$ radiation. Journal of agro-Environment Science. 27(6), 2325-2331 (2008) (in Chinese)

17. Cao, H.-X., Zhao, S.-L., Ge, D.-K., Liu, Y.-X., Liu, Y., Sun, J.-Y., Yue, Y.-B., Zhang, Z.-Y., Chen, Y.-L.: Discussion on development of crop models. Scientia Agricultura Sinica. 44(17), 3520-3528 (2011) (in Chinese)

18. Hou, Y.-H., Chen, C.-Y., Guo, Z.-Q., Hou, L.-B., Dong, Z.-Q., Zhao, M.: Establishment of dry matter accumulation dynamic simulation model and analysis of growth characteristic for high-yielding population of spring maize. Journal of Maize Sciences. 16(6), 90-95 (2008) (in Chinese)

19. Huang, Z.-X., Wang, Y.-J., Wang, K.-J., Li, D.-H., Zhao, M., Liu, J.-G., Dong, S.-T., Wang, H.-J., Wang, H.-J., Yang, J.-S.: Photosynthetic characteristics during grain filling stage of summer maize hybrids with high yield potential of $15000 \mathrm{~kg} \mathrm{ha}^{-1}$. Scientia Agricultura Sinica. 40(9), 1898-1906 (2007) (in Chinese)

20. Li, G.-Q., Tang, L., Zhang, W.-Y., Cao, W.-X., Zhu, Y.: Dynamic analysis on response of dry matter accumulation and partitioning to nitrogen fertilizer in wheat cultivars with different plant types. Acta Agronomica Sinica. 35(12), 2258-2265 (2009) (in Chinese) 